\title{
TERAPIA GÉNICA Y PRINCIPIOS ÉTICOS
}

\author{
Eduardo Rodríguez Yunta*
}

\begin{abstract}
Resumen: La terapia génica constituye una forma de manipulación genética que trata de corregir o disminuir los efectos que ocasionan enfermedades de origen genético. Existen grandes esperanzas en el desarrollo de este tipo de terapia, sobre todo para enfermedades somáticas de origen genético que no tienen curación. Pero hay también numerosas dificultades técnicas que no están del todo resueltas. No se ha demostrado todavía eficacia clínica y se pueden producir daños irreversibles en el organismo. Por una parte, existe la necesidad de regular por medio de protocolos que deben ser rigurosamente analizados por comités de evaluación ética y científica y, por otra, hace falta un diálogo entre países, con el fin de evitar una presentación exitista de la técnica en el mercado sin mencionar sus dificultades inherentes. Una de las preocupaciones mayores es que la aceptación paulatina de este tipo de terapia, y la eliminación de restricciones, permita el uso de la técnica para terapia génica germinal y para terapia génica de mejoría, cuya validez ética es cuestionada. Usar la terapia génica en células germinales conlleva el riesgo de introducir daños genéticos en generaciones posteriores.
\end{abstract}

Palabras clave: Terapia génica, manipulación genética, principios éticos

\section{GEN THERAPY AND ETHICAL PRINCIPLES}

\begin{abstract}
Gene therapy is a form of genetic manipulation which tries to correct or to diminish the effects caused by genetic diseases. There are great hopes for the development of this type of therapy, specially for somatic genetic diseases that has no cure, but there are many technical difficulties which are not yet solved. It has not yet been shown clinical efficacy and the technique may cause irreversible damages in the organism. On one hand, it is considered necessary to establish regulatory mechanisms to avoid possible abuse and the research protocols must be strictly analyzed by ethical and scientific review committees. On the other hand, at the international level, it is necessary a dialogue between nations in order not to present gene therapy in the market as a successful technique, without mentioning all the technical difficulties. One of the major concerns consists in that the gradual acceptance of this technique and the removal of restrictions may lead to the use of germ gene therapy and genetic enhancement, whose ethical validity is questionable. The use of germ gene therapy carries the risk of introducing genetic damages in posterior generations.
\end{abstract}

Key words: Gene therapy, genetic manipulation, ethical principles

\section{A TERAPIA GÊNICA E OS PRINCÍPIOS ÉTICOS}

Resumo: A terapia gênica constitui uma forma de manipulação genética que trata de corrigir ou diminuir os efeitos que ocasionam enfermidades de origem genética. Existem grandes esperanças no desenvolvimento deste tipo de terapia, sobretudo para doenças somáticas de origem genética que não tem cura. Existem, não obstante isso numerosos dificuldades técnicas que não estão totalmente resolvidas. Não se demostrou ainda a eficácia clínica e se pode causar danos irreversíveis no organismo. De um lado, existe a necessidade de regular por meio de protocolos que devem ser rigorosamente analisados por comitês de avaliação ética e científica, por outra, faz falta um diálogo entre países, para se evitar uma apresentação unilateral exitosa da técnica da técnica no mercado sem mencionar suas dificuldades inerentes. Uma das preocupações maiores é que a aceitação paulatina deste tipo de terapia, e a eliminação de restrições, permite o uso da técnica para terapia gênica germinal e para terapia gênica de melhora, cuja validade ética é questionada. Usar a terapia gênica em células germinais traz o risco de introduzir danos genéticos em gerações posteriores.

Palavras chave: Terapia gênica, manipulação genética, princípios éticos

* Doctor en Biología Celular y Molecular. Master en Teología, Especialidad Ética. Consultor del Programa Regional de Bioética OPS/OMS

Correspondencia: rodrigue@chi.ops-oms.org 


\section{Introducción}

Uno de los logros fundamentales que está consiguiendo el Proyecto del Genoma Humano es la identificación de las numerosas mutaciones que causan las enfermedades hereditarias, haciendo posible un preciso diagnóstico de las mismas. El proyecto está dando lugar a un mayor entendimiento tanto de los defectos causados por un solo gen como de las enfermedades multifactoriales, tales como el cáncer o la diabetes. La mayor parte de las enfermedades son influenciadas en algún aspecto por cambios en el genoma, si es que no son directamente causadas por estos cambios.

A través de la tecnología de recombinación genética, los científicos son capaces de alterar el material genético de organismos introduciendo ADN externo de la misma o de diferente especie. La ingeniería genética ha desarrollado un nuevo tipo de terapia que consiste en la administración de material genético en pacientes con la intención de corregir un defecto genético específico o de prevenir enfermedades, atacando la causa del defecto directamente. La terapia génica usa la ingeniería genética para introducir o eliminar genes específicos alterando o suplementando la acción de un gen anormal, reparándolo, introduciendo una copia del gen normal o introduciendo un gen que añada nuevas funciones o regule la actividad de otros genes actuando de forma terapéutica. Hay dos categorías diferentes: (a) terapia en la línea germinal, de forma que el cambio genético efectuado es heredable al afectar las células reproductivas. Esto se puede llevar a cabo ejerciendo el cambio en células germinales como el óvulo y el espermatozoide o en el zigoto o primeras divisiones celulares; y (b) terapia en células somáticas, por la que se efectúan cambios genéticos no heredables en cualquier célula somática (no germinal) del cuerpo. También se ha separado la terapia génica de la mejoría genética, cuando el cambio que se efec- túa no es por razones terapéuticas, sino buscando mejorar una cualidad o característica humana como el aspecto físico, el comportamiento, la inteligencia o la memoria.

A pesar de que la idea de la terapia génica en células somáticas es científica y médicamente atractiva por la posibilidad de sanar enfermedades que no tienen curación, en 13 años de investigación no se han logrado aplicaciones clínicas satisfactorias; lo que parecía una técnica promisoria, puede no serlo tanto. Existen numerosos protocolos de investigación y tratamiento por terapia génica en un buen número de países en la actualidad.

Por otra parte, la ética de la terapia génica ha sido debatida en artículos científicos y está también ligada a la opinión pública y política. Se ve la necesidad de regularla por los posibles abusos que pudieran darse debidos al mal uso de esta técnica.

\section{Terapia Génica Somática}

La terapia génica somática se basa en la transferencia de material genético a células somáticas como forma alternativa de tratamiento para mejorar la salud de las personas. Esta terapia está todavía en fase experimental. Puede ser la introducción de ADN o de ARN, o la introducción de células cuyo material genético ha sido modificado. La transferencia puede ser in vivo, in situ o ex vivo. In vivo consiste en la introducción de genes terapéuticos por medio de vectores a través del torrente circulatorio o células de la piel. In situ, cuando la modificación genética de las células del paciente se realiza introduciendo los genes terapéuticos directamente en el órgano defectuoso. Ex vivo consiste en la transferencia de genes en células viables que han sido temporalmente removidas del cuerpo, las cuales son reinsertadas en el organismo. La transferencia de un gen se puede lograr de diversas formas(1): 
1. Métodos físicos o químicos como la transmisión directa de ADN o de complejos de ADN como liposomas, conjugados moleculares o policationes. La ventaja es que se puede transferir ADN de gran tamaño, pero la eficiencia de transferencia es pequeña y tiene poca durabilidad en el interior de la célula por no integrarse en el genoma. También se usa el microbombardeo, que consiste en la aceleración a gran velocidad de partículas como el oro, que incluyen el ADN, y que se hacen impactar contra las células para favorecer la penetración.

2. Mediante un vector viral modificado de forma que no sea patogénico. Hay diversos tipos de virus que pueden ser usados como vectores: los retrovirus tienen la ventaja de que penetran efectivamente en las células en división y se integran en el material genético de la célula huésped sin introducir los genes virales; por tanto permiten una corrección permanente; además, se inserta solamente una copia del gen en cada célula. Las desventajas son que sólo se pueden integrar en células que se dividen activamente, hay dificultades en controlar y asegurar la expresión, el tamaño de los genes que se introducirán es limitado y existe potencial de daño al genoma por integrarse al azar en éste. Los adenovirus tienen la ventaja de que se logra con ellos un alto nivel de expresión, son relativamente fáciles de manejar, infectan un buen número de tipos celulares, incluyendo la capacidad de infectar células que no se están dividiendo. Las desventajas son que producen un alto nivel de rechazo inmunológico y que su genoma es muy complejo y no del todo comprendido, además de tener una vida corta por no integrarse en el genoma. Los virus adenoasociados se integran en sitios específicos del genoma, pueden infectar diferentes tipos de células, pero requieren de los genes virales para integrar- se; además, el tamaño del gen que pueden integrar es muy limitado. Los herpetovirus son neurotrópicos, se pueden usar en desórdenes neurológicos, pueden aceptar grandes segmentos de ADN y se mantienen como elementos extracromosómicos, pero son virus complejos. Los poxviruses pueden introducir un amplio segmento de ADN y su nivel de expresión es alto; el problema es que son altamente inmunogénicos.

3. Introducción de cromosomas artificiales. Se encuentra en fase de experimentación. Permitiría una acción permanente de los genes introducidos sin el problema de causar posibles daños por inserción al azar en el genoma, como ocurre con los retrovirus.

Debido a que no se efectúa ningún cambio en las células germinales, se trata de un tratamiento que sólo afecta al individuo y no a su descendencia. Al alterar el material genético de las células somáticas, la terapia génica puede corregir la causa fisiológica de la enfermedad. En principio, la terapia génica somática puede ser aplicable para aquellas enfermedades para las que no existe un tratamiento efectivo o las expectativas de efectividad son muy bajas.

Desde 1990 se ha iniciado la terapia en células somáticas. La enfermedad elegida para el primer ensayo clínico fue la inmunodeficiencia severa combinada, que causa una severa deficiencia en la función inmunológica, de forma que la persona sucumbe prontamente por infecciones. Los pacientes fueron tratados introduciendo un retrovirus en el que se incluyó una copia del gen de la enzima adenosina desaminasa (ADA), proteína cuya carencia produce la enfermedad(2). El tratamiento fue un éxito parcial ya que una de las pacientes tratada recuperó la funcionalidad del sistema inmunitario, pero la mejora fue sólo temporal. Actualmente se ha suspendido la terapia génica 
de esta enfermedad en Francia y Estados Unidos por posibles efectos peligrosos, ya que uno de los niños tratados ha desarrollado una enfermedad similar a la leucemia ${ }^{1}$. Desde entonces, y hasta 1999, ya se habían efectuado 534 protocolos clínicos en el mundo y 3464 individuos habían recibido tratamiento por transferencia génica(1). La mayoría de los ensayos clínicos se han realizado sobre el cáncer y hasta ahora con poca efectividad, aparte de que se necesita que sea acompañada siempre por terapias adicionales. La técnica de transferencia génica ofrece un gran potencial para la terapia de enfermedades causadas por mutaciones genéticas, aunque todavía no se ha demostrado una eficacia clínica. Las enfermedades a las que se puede aplicar esta técnica son varias y se las puede distinguir según categorías:

1. Enfermedades monogénicas originadas por mutaciones en un solo gen, que causan pérdida de la función de la proteína que codifican y son de naturaleza recesiva. Aunque son infrecuentes en la población, estas mutaciones son responsables de un gran número de enfermedades crónicas, por ejemplo, de las hemofilias, la anemia falciforme, las deficiencias inmunológicas (como la deficiencia en adenosina desaminasa), la hipercolesterolemia familiar -debida a defectos en el receptor de grasas LDL- y la fibrosis quística $(3,4)$.

2. Enfermedades multifactoriales, en que varios genes están envueltos en la expresión de la enfermedad, por ejemplo, las enfermedades coronarias, la hipertensión y la diabetes(5-7).

3. Enfermedades adquiridas, como el cáncer, que es una enfermedad genética a nivel celular. Hay tres clases de genes importantes relacionados con el surgimiento de cáncer

VOA News (3 de octubre de 2002). por mutaciones en los mismos: protooncogenes, genes supresores de tumores y genes de reparación de ADN. Existen muchas dificultades para obtener efectividad clínica introduciendo genes normales de aquellos que han sido mutados como, por ejemplo, efecto dominante de algunas de las mutaciones, dificultad de llegar a toda la masa tumoral y a las metástasis, y alto grado de inducción mutagénica. Debido a este problema se usan aproximaciones indirectas tales como: la introducción de genes de citokinas y otros productos inmunomodulatorios que activan una respuesta inmune; la introducción de genes activadores de drogas dentro de las células tumorales, también llamada "terapia de genes suicida"; la introducción de genes resistentes a quimioterapia en células de la médula ósea que van a ser usadas para trasplante; inactivar oncogenes normalizando el ciclo celular y, finalmente, provocar la muerte celular en células tumorales $(4,8)$. Como estrategia directa de reemplazo, el más usado ha sido el gen supresor de tumores p53, que es capaz de inhibir el crecimiento celular y la angiogénesis, y de producir muerte celu$\operatorname{lar}(9,10)$.

4. Enfermedades neurológicas degenerativas, como las enfermedades de Parkinson y de Alzheimer(11-13).

5. Enfermedades infecciosas, como el herpes, la hepatitis o el SIDA. Las estrategias de terapia génica consisten en obtener vacunas, introducir genes que obstaculicen la replicación del virus, activar el sistema inmune, impedir que el virus infecte a células sanas, hacer terapia con genes suicidas, introducir genes que produzcan ribozimas que degraden el ARN viral y expresar genes que provean protección a las células para no ser infectadas $(14,15)$. 
6. Trasplante de órganos. Se pueden introducir genes para antígenos del donante en el huésped, que hagan que éste tolere inmunológicamente al órgano donante cuando sea trasplantado(1).

Para que la terapia génica sea efectiva se necesita resolver ciertas dificultades técnicas que no están del todo resueltas: 1) Introducir el gen en el tipo celular o tejido específico que está afectado. 2) Lograr el nivel de expresión (producción de proteína) requerido para lograr la corrección de la enfermedad; el gen introducido debe tener un apropiado promotor para que se pueda sintetizar ARN. 3) Lograr una regulación continuada y efectiva de la expresión del gen introducido de forma que ésta se mantenga hasta que la enfermedad sea corregida. 4) Procurar una adecuada localización subcelular y un procesamiento adecuado del producto génico. 5) No hay un buen mecanismo de identificación de las células que han sido transformadas efectivamente por el nuevo gen.

Otra línea de investigación en desarrollo consiste en el uso de células madre, ya que se ha probado que pueden reemplazar células de diferentes tejidos. La estrategia para el uso de células madre en terapia génica consiste en sacarlas del cuerpo, hacerlas dividir en cultivos e introducir el gen con vectores apropiados. Si se ve que han sido exitosamente modificadas genéticamente, se introducen de vuelta en el cuerpo del paciente después de hacerlas crecer y multiplicarse. La ventaja de este método sobre la introducción del vector con el gen directamente en el cuerpo está en que los investigadores pueden ejercer un mayor control, pueden regular programando de qué forma se quiere producir el agente terapéutico y seleccionar fuera del cuerpo las células genéticamente modificadas adecuadas, es decir, aquellas que produzcan el agente terapéutico en suficiente cantidad. En general, fuera de algunas excep- ciones, no se han conseguido buenos resultados terapéuticos hasta ahora con el uso de células madre adultas, porque no se produce el agente terapéutico en suficiente cantidad y porque, con el tiempo, el gen que se introduce en el cromosoma es desactivado por procesos celulares que alteran la estructura del $\operatorname{ADN}(16)$. Además, las células madre adultas tienen más limitada su capacidad para dividirse; se cree que debido en parte a la actividad de la enzima telomerasa que aumenta la longitud de los telómeros de los cromosomas, como ha sido demostrado en el ratón $(17,18)$. Se piensa que esto cambiaría si se usaran células madre embrionarias. La ventaja de usar estas últimas es que se trata de una población celular que se renueva a sí misma y reduce o elimina la necesidad de repetir la terapia génica varias veces: se dividen activamente y pueden proliferar por largos periodos en cultivos en laboratorio manteniendo su pluripotencialidad(19), mientras que las adultas no. El vehículo más usado para introducir los genes son los retrovirus que se insertan en el cromosoma celular, pero lo hacen sólo si la célula se divide. Además, para producir suficiente cantidad de agente terapéutico se necesita que muchas células lo produzcan, lo cual requiere multiplicarse activamente. Se cree que cuanto más primitivas sean las células, mayor es su capacidad proliferativa y mejor uso se puede hacer para la terapia génica. Sin embargo, esto plantea el problema ético de que para usar células embrionarias, un embrión ha de ser destruido.

\section{Terapia Génica Germinal}

La terapia en células germinales ha sido realizada, hasta ahora, únicamente en animales. Técnicamente, la terapia en células germinales es más difícil que en células somáticas, ya que se debe demostrar que no va a haber efectos adversos en el desarrollo. Se ha sugerido utilizar la terapia génica en células germinales para evitar 
que se desarrollen enfermedades en futuros individuos. También se podría ejercer la alteración genética en el cigoto o en el embrión en los primeros estadios del desarrollo, antes del proceso de diferenciación celular y el desarrollo de órganos(20). En los primeros estadios del desarrollo el cambio genético afectará todos los tejidos y órganos, incluyendo las células germinales del adulto que se va a desarrollar. El cigoto o embrión es accesible a alteraciones genéticas por medio de la técnica de fecundación in vitro, práctica que se llevaría a cabo en conjunción con un diagnóstico genético preimplantacional. Otros han propuesto realizar quimeras añadiendo líneas celulares embrionales que no tengan la mutación que se quiera corregir, con la posibilidad de que de estas células embrionales se derivase la línea germinal(21). Con esta última técnica el problema es que se originaría un individuo con una línea germinal con un componente genético diferente.

Pero, en el presente estado de la tecnología, llevar a cabo la terapia génica germinal conlleva el riesgo de dañar las futuras generaciones. Cualquier pequeño error se magnifica, ya que las células de los genes manipulados van a dar lugar a cada célula individual en el cuerpo. Los errores y alteraciones en el material genético quedan para la siguiente generación, lo cual añade una gran responsabilidad. Habría que lograr una recombinación homóloga exacta en que se intercambiase el gen dañado por uno funcional en el mismo lugar cromosómico; pero hasta ahora, por la terapia génica, el nuevo gen se introduce en cualquier parte del genoma con el riesgo de que caiga en la ruta de otro gen y afecte al proceso de desarrollo o induzca cáncer(22,23). A causa de que la actividad de un gen depende del contexto en que se encuentre, es imposible predecir lo que puede ocurrir con la inserción de un gen en un lugar diferente de su contexto original, como ocurre con la tecnología de terapia génica; esto genera el grave riesgo de producir daños irrever- sibles en el organismo y que se transmitan a generaciones venideras(24). La expresión de un gen es el resultado de interacciones muy complejas, tanto celulares como con el organismo entero, y es influenciada por condiciones externas. El mismo gen puede dar lugar a diferentes proteínas bajo condiciones diferentes.

Se ha experimentado con recombinación homóloga de fragmentos de ADN (técnica SFHR) para sustituir lesiones pequeñas (tipo adición, deleción o reversión de unas pocas pares de bases) en genes que causan enfermedades monogénicas (como anemia falciforme y fibrosis quística), en que la maquinaria recombinacional de la célula huésped dirige la integración del fragmento de ADN terapéutico $(25,26)$. La dificultad está en conseguir el suficiente número de células modificadas para que sea clínicamente relevante y se revierta la enfermedad. Si se lograse perfeccionar esta técnica de manera que ofrezca la seguridad suficiente, abriría la posibilidad de realizar protocolos de terapia génica germinal en seres humanos para enfermedades monogénicas.

\section{Terapia Génica de Mejoría}

Es previsible la posibilidad de ejercer alteraciones genéticas no terapéuticas, intentando mejorar la condición genética del individuo al insertar un gen que mejore ciertas cualidades, como la belleza, la inteligencia, o la prolongación de la vida(20). Esto es llamado "terapia génica de mejoría". Algunos autores defienden el uso de esta técnica, ya que sería muy difícil trazar límites y poner restricciones en la sociedad(27). Hoy en día no tenemos aún los medios técnicos para inducir los cambios mencionados anteriormente, pero es posible que con la información que se está obteniendo por el proyecto del genoma y con el perfeccionamiento de la terapia génica algunos de estos cambios sean más accesibles. 
Para algunos filósofos no hay base moral para restringir al ser humano en el propósito de alterar su naturaleza. Si existe la posibilidad de alterarla a través de la tecnología genética, se debe considerar como una forma de librarse de las dificultades que presenta nuestra naturaleza para poder alcanzar nuestro destino como personas(28). Se ha aconsejado que no debiéramos perder de vista el potencial que tiene la mejoría genética para el bienestar del ser humano(29). La mejoría genética podría ser beneficiosa, tanto para el individuo como para la sociedad, una vez que la tecnología esté disponible. Algunos ejemplos de esta posibilidad son: 1) Mejorar el sistema inmunológico del cuerpo para resistir las infecciones y el cáncer; 2) reducir la necesidad del cuerpo de dormir sin perder la capacidad de atención cuando se está despierto; 3) incrementar el poder de la memoria; 4) reducir las tendencias agresivas y aumentar las tendencias a la generosidad y la paz; 5) retardar los efectos de la vejez y prolongar los años de vida(29). De hecho, existe una separación que hay que delimitar entre la mejoría, la enfermedad o la prevención para mejorar las defensas del cuerpo en contra de la enfermedad. Visto el tipo de sociedad en que vivimos, en que hay formas diversas de entender lo que es moral, algunos autores predicen que las decisiones descansarán en el individuo(30); pero, más bien, habría primero que buscar un consenso en la sociedad para definir los límites entre lo que es terapéutico y la mejoría genética, para luego pasar a una reflexión ética.

\section{Reflexión Ética}

\section{Terapia Génica Somática}

En principio, los estándares éticos de investigación clínica en terapia génica somática deben ser los mismos que se demandan en todas las áreas de la medicina. Siempre el primer principio ético que se debe considerar es el respeto a la integridad y la dignidad de las personas a quienes se realiza el tratamiento. El problema ético de la terapia génica somática está relacio- nado con el llamado "encarnizamiento terapéutico", estimándose que sólo los enfermos muy graves y sin otra alternativa podrían ser beneficiados por esta terapia en el estado actual de la técnica.

La eficacia clínica no ha sido todavía demostrada; a pesar de los numerosos protocolos ya realizados se pueden producir daños irreversibles. No todos los tratamientos con terapia génica han sido exitosos, se ha visto que hay riesgos(31), por ejemplo: infección por el vector viral, inducción de cáncer por inserción en un gen supresor de tumores o por activar un oncogen, interrupción de un gen normal con consecuencias negativas como inducir otra enfermedad, contaminación bacteriana, respuesta inmunológica con reacción inflamatoria y sólo parcial corrección de la enfermedad genética convirtiendo una condición fatal en una crónica progresiva $(22,23,32)$. Debido a estos riesgos, se han establecido comités de evaluación ética y de seguridad en la experimentación clínica con la terapia génica en numerosos países. Es necesario, por ejemplo, asegurar el proceso de obtener consentimiento informado, la pureza del material que se administra, los daños que podrían resultar en contraposición con los beneficios. También asegurar que -siempre que sea posible- se haya estudiado previamente en modelos animales, que sea posible medir los efectos del tratamiento y haya un seguimiento, que se proteja a los grupos vulnerables, que la enfermedad tratada sea de naturaleza seria con expectativas bajas de vida para el paciente, que el laboratorio que lo realice tenga los medios y el personal adecuado y haya un control minucioso de los protocolos, que los vectores utilizados sean inocuos y que se eviten inserciones de $\mathrm{ADN}$ en la línea germinal. Además, las comisiones que analizan los datos deben ser independientes del grupo investigador(33). 
El uso de esta terapia puede ser apoyada por los principios de autonomía, beneficencia y justicia. Para respetar la autonomía, se debe obtener consentimiento libre e informado del paciente, respetando también la privacidad y la confidencialidad de los datos obtenidos; se debe evaluar si los beneficios son mayores que los riesgos, de manera que se actúe por beneficencia, y hay que considerar que, en justicia, todo paciente tiene derecho a recibir tratamiento cuando su vida está en riesgo. El tema de la justicia equitativa es la más difícil de resolver, más si consideramos a los países subdesarrollados y a los países en vías de desarrollo; es difícil que haya una cierta equidad social en el uso de esta técnica. Se trata de una terapia costosa y en muchas ocasiones de por vida, por lo tanto, no está al alcance de muchos. En este sentido, los países desarrollados deben tomar conciencia de las dificultades en los países en desarrollo, procurando disminuir la distancia que separa la medicina para los ricos de la de los pobres. Hace falta además un diálogo entre los países, de manera que no se presente el producto de la terapia génica como si fuera a tener un gran éxito, sin mencionar todas las dificultades inherentes a la técnica.

Una de las preocupaciones mayores es el peligro de lo que se denomina "plano inclinado resbaladizo" (slippery slope). Cuando se acepta una técnica siempre se inicia con restricciones y limitaciones, pero luego se da paso a la aceptación paulatina y la eliminación de restricciones. El temor es que fácilmente se podría pasar de la terapia génica somática a la terapia génica de mejoría.

\section{Terapia Génica Germinal}

La terapia génica germinal no es una técnica segura como para realizarla en la actualidad. La Asociación Americana para el Avance de la Ciencia es partidaria de una moratoria en el uso de esta terapia y ha urgido al gobierno de Estados Unidos para que cree un panel que prevenga la realización de experimentos con alto riesgo en la línea germinal ${ }^{2}$, la razón: podría causar daños que pasasen de una generación a la siguiente. El Consejo de Europa prohíbe intervenciones en la línea germinal, pero deja la puerta abierta para posibles excepciones en el futuro(34). Además de los daños ya mencionados en la terapia génica somática, se añade la posibilidad de afectar el desarrollo por inserción de secuencias de ADN en genes que están relacionados con el desarrollo.

Un problema es el consentimiento informado. La pregunta es si tenemos derecho a decidir por las generaciones futuras. Se ha objetado que la terapia génica germinal viola la dignidad humana porque cambia el contenido genético de las siguientes generaciones cuyo consentimiento no puede ser obtenido y cuyo interés es difícil de dilucidar(35). También afectaría a la integridad del patrimonio genético humano, seleccionando y determinando características de las futuras generaciones. Sin embargo, si se perfeccionara la técnica, se podría aceptar la terapia génica germinal ya que técnicamente habría que lograr una recombinación homóloga exacta en que se intercambiase el gen dañado por el normal. Sería más simple de realizar una sola vez que no tener que llevar a cabo la terapia génica somática en cada generación. Si el propósito es prevenir el sufrimiento humano y la muerte prematura (y dado que éstos son valores universales y por tanto no requieren previo consentimiento) actuaríamos por el mejor interés en beneficio de generaciones futuras. En este caso prevalecería el principio de beneficencia por sobre el de autonomía. Además, hay enfermedades como las que implican al sistema nervioso central, en que una intervención temprana en el embrión sería el único medio de conseguir una terapia efectiva, ya que sería muy complicado reparar genéticamente las células nerviosas después del

AAAS 18 de Septiembre, 2000. 
nacimiento. Pero, en el estado actual de la técnica, éticamente la posibilidad de daño pone al principio de no maleficencia por encima del de beneficencia, debido al riesgo para las generaciones futuras.

\section{Terapia Génica de Mejoría}

Hay dos consideraciones que diferencian a la terapia génica somática de la mejoría genética y que afectan a la dignidad humana:

1. El riesgo médico a que se expone la persona es mayor con la terapia génica de mejoría. Aparte del riesgo relativo a la técnica, se añade el hecho de que introducir un gen para que sintetice más cantidad de un producto ya existente puede afectar negativamente a otros procesos bioquímicos y poner en peligro el equilibrio metabólico. En el balance entre riesgos y beneficios, los beneficios son menos claros que en la terapia génica somática.

2. Aplicar la mejoría genética conlleva una serie de problemas difíciles de resolver: ¿Qué genes se deben transferir? ¿A quién o a qué grupo social realizamos la transferencia génica, con el peligro de que aumentemos las diferencias sociales? ¿Cómo evitar la discriminación contra los individuos que reciban el gen o contra los que no lo reciban? La aceptación en la sociedad de la mejoría genética llevaría, muy probablemente, a la discriminación y a la devaluación de ciertas categorías de personas cuyos genes no se considerarían dignos de imitar. No hay criterio objetivo, libre de prejuicios, que pueda establecer qué cualidades son mejores que otras. Si se tuviese acceso libre a esta técnica, existe el peligro de utilizarla para dar ventaja a ciertos privilegiados. Se podría, por ejemplo, incrementar la inteligencia de ciertas personas o mejorar las capacidades físicas de atletas. Fácilmente se- ría una forma de ejercer discriminación. Habría un reforzamiento biológico de las distinciones de clase, ya que, con casi toda seguridad, el mejoramiento genético estaría sólo al alcance de los pudientes. Esta técnica podría ser usada para seleccionar ciertas características humanas creando una cierta clase social, con la correspondiente devaluación de otras características que no serían adecuadamente valoradas. No se ve cómo podría salvarse el principio de justicia equitativa, sobre todo si lo medimos a nivel internacional. Además, hay que añadir que, en el estado actual de la tecnología, no se justifica la mejoría genética porque se pueden producir daños irreversibles en el organismo. Sólo se justifica emplear la ingeniería genética en el caso de intervenciones terapéuticas de enfermedades que amenazan la vida de la persona.

El genoma es compartido por todos los seres humanos, indiferentemente de la raza, por lo que debería haber una regulación internacional que limitara la posibilidad de manipulación genética. Es de interés para toda la humanidad poner límites y, por tanto, se necesita una normativa internacional. De otro modo, en un futuro podría ocurrir la aparición de razas mejoradas genéticamente en ciertos países en que hubiera permisividad en la manipulación genética. El propósito de regular a nivel internacional es evitar el incremento de las diferencias sociales entre países y satisfacer el interés común de la humanidad de proteger el genoma. Una regulación internacional podría proveer, al menos, un mínimo de protección y evitar el abuso de unos países sobre otros. Habría que pensar, en un futuro próximo, en implementar leyes internacionales de protección del genoma por ser patrimonio de toda la humanidad ${ }^{3}$.

Así ha sido declarado por la UNESCO en la Declaración Universal sobre el Genoma Humano y los Derechos Humanos (1997). 


\section{Referencias}

1. Fry JW, Wood KJ. Gene Therapy: Potential Applications in Clinical Transplantation. Expert Reviews in Molecular Medicine 1999. Cambridge University Press. [Sitio en Internet] Disponible en http://wwwermm.cbcu.cam.ac.uk/99000691h.htm Acceso en abril de 2003.

2. Anderson WF. Human Gene Therapy. Science 1992; 256: 808-813.

3. Griesenbach U, Alton EW. Recent Progress in Gene Therapy for Cystic Fibrosis. Current Opinion in Molecular Therapeutics 2001; 3: 385-389.

4. Rubanyi GM. The Future of Human Gene Therapy. Molecular Aspects Medicine 2001; 22: 113-142.

5. Hiltunen MO, Turunen MP, Yla-Herttuala S. Gene Therapy Methods in Cardiovascular Diseases. Methods Enzimology 2002; 346: 311-320.

6. Feldman ILJ, Taheil O, Steg G. Perspectives of Arterial Gene Therapy for the Prevention of Reestenosis. Cardiovascular Research 1996; 324: 194-207.

7. Muzzin P, Eisensmith RC, Copeland KC, Woo SL. Correction of Obesity and Diabetes in Genetically Obese Mice by Leptin Gene Therapy. Proceedings National Academy of Science 1996; 93: 1480414808.

8. Marchisone C, Pfeffer U, Del Grosso F, et al. Progress Towards Gene Therapy for Cancer. Journal of Experimental Clinical Cancer Research 2000; 19: 261-270.

9. Lane DP, Lain S. Therapeutic Exploitation of the p53 Pathway. Trends Molecular Medicine 2002; 8: S38-S42.

10. Xu L, Pirollo KF, Chang EH. Tumor-targeted p53-Gene Therapy Enhances the Efficacy of Conventional Chemo/Radiotherapy. Journal of Control Release 2001; 74: 115-128.

11. Segovia J. Gene Therapy for Parkinson's Disease: Current Status and Future Potential. American Journal of Pharmacogenomics 2002; 2: 135-146.

12. Wang ZH, Ji Y, Shan W, et al. Therapeutic Effects of Astrocytes Expressing both Tyrosine Hydroxylase and Brain-derived neurotrophic Factor on a Rat Model of Parkinson's Disease. Neuroscience 2002; 113: 629-640.

13. Martin-Rendon E, Azzouz M, Mazarakis ND. Lentiviral Vectors for the Treatment of Neurodegenerative Diseases. Current Opinion Molecular Therapeutics 2001; 3: 476-481.

14. Palug G. Combined Strategies for Gene Therapy of AIDS. Gene Therapy 1997; 4: 179-180.

15. Schmitz V, Qian C, Ruiz J, et al. Gene Therapy for Liver Diseases: Recent Strategies for Treatment of Viral Hepatitis and Liver Malignancies. Gut 2002; 50: 130-135.

16. Chen WY, Townes TM. Molecular Mechanism for Silencing Virally Transduced Genes Involves Histone Deacetylation and Chromatin Condensation. Proceedings National Academy of Science U. S. A. 2002; 97: $377-382$.

17. Armstrong L, Lako M, Lincoln J, et al. MTert Expression Correlates with Telomerase Activity During the Differentiation of Murine Embryonic Stem Cells. Mechanisms Development 2000; 97: 109-116. 
18. Yoder MC, Hiatt K. Murine Yolk Sac and Bone Marrow Hematopoietic Cells with High Proliferative Potential Display Different Capacities for Producing Colony-Forming Cells ex Vivo. Journal of Hematology Stem Cell Research 1999; 8(4): 421-430.

19. Amit M, Carpenter MK, Inokuma MS, et al. Clonally Derived Human Embryonic Stem Cells Lines Maintain Pluripotency and Proliferative Potential for Prolonged Periods of Culture. Developmental Biology 2000; 227: 271-278.

20. Baird PA. Altering Human Genes: Social, Ethical and Legal Implications. Perspectives in Biology and Medicine 1994; 37: 566-575.

21. Bonnicksen AL. National and International Approaches to Human Germ-Line Gene Therapy. Politics and the Life Sciences 1994; 13: 1-11.

22. Doerfler W. A New Concept in (Adenoviral) Oncogenesis: Integration of Foreign DNA and its Consequences. Biochemistry Biophysics Acta 1996; 1288: F79-99.

23. Weis RA. Retroviruses and Human Cancer. Seminars Cancer Biology 1992; 3: 321-328.

24. Ho M-W. Genetic Engineering, Dreams or Nightmares. Bath: Gateway Books; 1998.

25. Goncz KK, Prokopishyn NL, Chow BL, et al. Application of SFHR to Gene Therapy of Monogenic Disorders. Gene Therapy 2002; 9: 691-694.

26. Sangiulo F, Bruscia F, Serafino A, et al. In Vitro Correction of Cystic Fibrosis Epithelial Cell Lines by Small Fragment Homologous Replacement (SFHR) Technique. BMC Medical Genetics 2002; 3: 8.

27. Miller HI. Gene Therapy for Enhancement. The Lancet 1994; 344: 316-317.

28. Fletcher J. Moral Problems and Ethical Issues in Prospective Human Gene Therapy. Virginia Law Review 1983; 69: 515-546.

29. Nelson JR. On the New Frontiers of Genetics and Religion. Grand Rapids, Michigan: William B. Eerdmans Publishing Company; 1994: 115.

30. Engelhardt HT. Germ-Line Genetic Engineering and Moral Diversity: Moral Controversies in a PostChristian World. Social Philosophy and Policy 1996; 13: 47-62.

31. Fox M. Gene Therapy under Fire. ABC News January 31, 2000. [Sitio en Internet]. Disponible en http:/ /abcnews.go.com/sections/living/DailyNews/genetherapy_000130.html Acceso en abril de 2003.

32. Marshall E. Gene Therapy Death Prompts Review of Adenovirus Vector. Science 1999; 286: 22442245.

33. Dettweiler U, Simon P. Points to Consider for Ethics Committees in Human Gene Therapy Trials. Bioethics 2001; 15: 491-500.

34. Nelki DS. European Bioethics Convention. Gene Therapy Newsletter 1994; sept-oct: 22-23.

35. Whelan WJ. Genetics, Ethics and Human Values. FASEB Journal 1995; 9: 699-700. 